\title{
Cycocel Induced Lignin Deposition in Cotton Cells and its Role in Crop Growth
}

\author{
Santosh Kumari ${ }^{1^{*}}$ and Vipin Kumar Verma ${ }^{2}$ \\ ${ }^{1}$ Division of Plant physiology, Indian Agricultural Research Institute, Delhi, India \\ ${ }^{2}$ Department of Pharmacology, All India Institute of Medical Sciences, New Delhi, India \\ *Corresponding author
}

\begin{abstract}
A B S T R A C T
Keywords

Anatomy, Cotton, Cycocel, Growth, Lignin, Root, Stem

Article Info

Accepted:

12 February 2019

Available Online:

10 March 2019

Cycocel reduced internode length accompanied with increased stem, root and leaf thickness. Cycocel remarkably added cells to phloem fiber, xylem fiber and xylem vessels in stem and root of treated plants. S-lignin, Glignin and $\mathrm{H}$-lignin were noticed in retardant treated suppressed stem tissue of cotton.
\end{abstract}

\section{Introduction}

Cotton is grown for textile fiber and oil for food. Cotton sticks are used as fuel and seed cover as cake for animal feed. The potential as a feedstock for paper production and biofuels generate interest in the composition of cotton plant. The lignin deposition is generally associated with secondary cell walls of xylem vessels and fibers in angiosperm provide mechanical support and protect against biotic and abiotic stresses. Cotton may prove a useful system for the study of the control of lignin quality and quantity by plant growth regulators. The study was carried out to understand Cycocel induced lignin deposition in cotton cells and its role in crop growth. How does cycocel affect growth and development of cotton plant in commercial production for more efficiency and profitability along with nutrient management?

\section{Materials and Methods}

Five seeds of cotton were grown in earthen pots filled with $12 \mathrm{~kg}$ field soil mixed with manure in pot house under natural environment on $20^{\text {th }}$ May and 20 $0^{\text {th }}$ June 2017. One plant was maintained in each pot after thinning in first sowing and two plants in second sowing to confirm the results. Cycocel treatment was given as $1 \mathrm{ml} /$ liter water as 
foliar spray once on whole plant surface at 7 8 leaves stage on $35^{\text {th }}$ day after sowing in each sowing. $1 \mathrm{~g}$ urea per/pot and $1 \mathrm{~g}$ potash per pot was applied along with irrigation water for treatment of nitrogen $(\mathrm{N})$ and potassium $(\mathrm{K})$. Anatomical observations were made at first square formation stage in control as well as cycocel treated plants.

Fresh samples of root, stem and leaves from control and cycocel treated plants were used for light microscopy (Nikon, Tokyo, Japan) transverse sections were cut by hand and stained in saffranin dissolved in water). These plants were used for photographic data of root length and plant height, compactness and branching patterns. Anatomical data from stem and root has been analysed for lignin deposition.

\section{Results and Discussion}

Cycocel treated plants showed the symptoms of leaf senescence, dropping leaves, stomatal closure and cessation of transpiration for a week (Fig. 1A, B and J), new leaves originated from the nodes bearing older leaves that wilted, dried and shed after mobilization of their metabolites. Crop growth, dry matter accumulation and productivity are influenced by photosynthetic efficiency and total leaf area. Our result indicated that Cycocel retarded growth may be tailored with micronutrient doses in the management of crop growth stages in cotton production system. Potassium $(\mathrm{K})$ is one of the essential micronutrient required for normal plant growth and development. K affects water relations and osmotic adjustment, cell elongation, stomatal conductance, photosynthesis, solute transport, protein synthesis and acts as a cofactor for a number of metabolic enzymes (Mengel and Kirby, 2001; Marschner, 2012). Present study showed that $\mathrm{K}$ affected the metabolic processes and reversed the retardant effect to some extent on internode elongation, root elongation and production of reproductive organ i.e. flower/boll formation as strong metabolic sink (Fig. 1F). Potassium affected turgor pressure and orientation of leaf in regenerated stem of cycocel treated plants, the emerging leaves showed the turgor mediated downward folding of leaf lobes (Fig. 1M) towards each other like closing umbrella during evening and opening of lobes in the day light. Same amount of nitrogen (N) application extended vegetative growth as leaf area formation and root elongation three times that of control (Fig. 1E) subsequently led to delay in reproductive growth i.e. formation of square, flower and bolls.

Cycocel treated cotton plant survived for one month under water logged conditions and survived 15 days more than control plants hence proved effective under excess water stress. Our photography and visual observation revealed that new leaves formation by shedding old ones sprayed with cycocel prolonged the survival of plant (Fig. $1 \mathrm{~K} \& \mathrm{~L}$ ). Our observation suggest that new lateral roots emerged from the lenticels close to the root shoot junction when tip of the primary root was cut and shoot was immersed in tap water along with mature control plant at reproductive stage i.e. flower formation in both plants and without main root tip; cytokinin transported from the roots to the stem helped in shoot formation by new leaves emergence from the apical meristem and dormant older nodes devoid of leaves i.e. shedding. Intermodal length of newly formed shoot inherited the cycocel effect and apical dominance was displayed by the growing stem tip producing only leaves reverting to vegetative growth from reproductive phase (one flower was produced) when the shoot was immersed into water. The leaves emerging at older nodes and branches were three lobed and smaller in size indicating remobilization of assimilates (limited) from 
roots and stem to the new organs. A leaf formed at the lateral branch terminal was generally simple lamina without any lobe. Subsequently formed leaves from the new stem nodes were bigger in size with five lobes. Number of lobes in leaf lamina decreased towards the stem apex again indicating limited nutrients. When potassium was supplied at the emerging three lobed leaf stages stipule formation occurs at the base of this and all newly formed leaves; the particular leaf lamina was enlarged in size showing interveinal yellowing. Newly formed leaves had round tip enlarged leaf lobes showing nyctinastic movements opening in horizontal direction in light and sleeping in vertical downward position/ closing the stem apex in the darkness. These leaves followed circadian rhythm which is controlled by the biological clock of these plants. A number of metabolic pathways are regulated by the circadian clock. Node number increased with heavy nitrogen while height increased with heavy irrigation i.e. turgor maintenance. Potassium uptake by root cell plasma membrane transporters have been shown to improve cell turgor under osmotic stress.

Osmotic adjustment is a key trait for maintenance of favorable water status, cellular turgor potential and water retention and is positively correlated with drought tolerance. Potassium was shown to improve stomatal conductance, water status, photosynthetic rate, quantum yield of PSII, higher antioxidant enzyme activities and increased proline accumulation under water stress in cotton leaves (Zahoor et al., 2017). Sucrose is an osmolyte that replaces $\mathrm{K}+$ in the guard cells and open stomata during middle of the day. It is generally accepted that most of the sugar is derived from mesophyll cells. As sucrose accumulates in the apoplast, its osmotic effect drives water efflux from guard cells decreasing stomatal aperture and inversely coordinating photosynthesis and transpiration (Talbott and Zeiger, 1996; Lu et al., 1997).

Our anatomical analysis revealed that suppression of internode length extended the stem and root diameter. Lignin contents that were genetically programmed for normal internode length were distributed as increased lignin synthesis in increased number of cells in xylem fiber, phloem fiber and pith cells (Fig. 2 and 3) Three types of lignin color were observed in xylem vessels (G-lignin), phloem cells (S-lignin) and pith cells (H-lignin) in cycocel treated stem tissues. Small amount of H-lignin (Xu et al., 2011) and S and G-lignin have been reported by Macmillan et al., (2013) in stem tissue of cotton. H-lignin was missing in stem sections of control plants. Number of cell layers was significantly reduced in xylem fibers and xylem vessel diameter was affected. The presence of lignin in stem cells in control plants and additional lignin in stem tissue bearing heavy leaves on compact stem with bushy appearance and absence of lignin in white cotton fiber packed in strong compact locules of cotton bolls clearly signifies the role of lignin in mechanical support under diverse environments. This study further reveals the role of growth retardant in secondary metabolism that indicates plant underwent a kind of stress and survival strategy adopted by plants by increasing root diameter and storage of assimilates under a combination of various stresses (high temperature, light and water stress). A critical role for lignin has been deduced in cotton disease resistance and rapid accumulation of flavonoids a phenyl propanoid product suggested their role as signal molecules (Xu et al., 2011). Cambial activity could be increased by shift in the hormone levels especially cytokinin (Ismaeil, 1995) that could have increased the translocation of $\mathrm{N}, \mathrm{P}, \mathrm{K}$ and photosynthates to the growing organs of the plant (Marschner, 2012) (Fig. 4). 

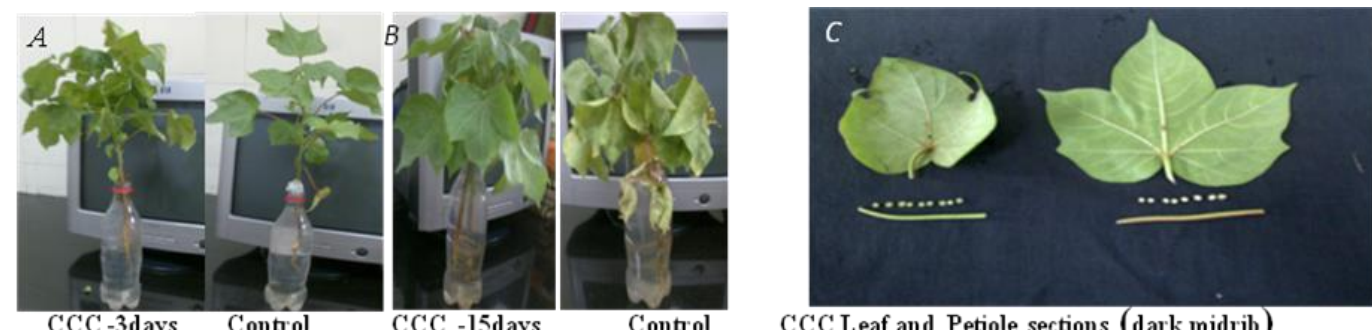

CCC-3days Control

CCC -15days

Control

CCC Leaf and Petiole sections (dark midrib)
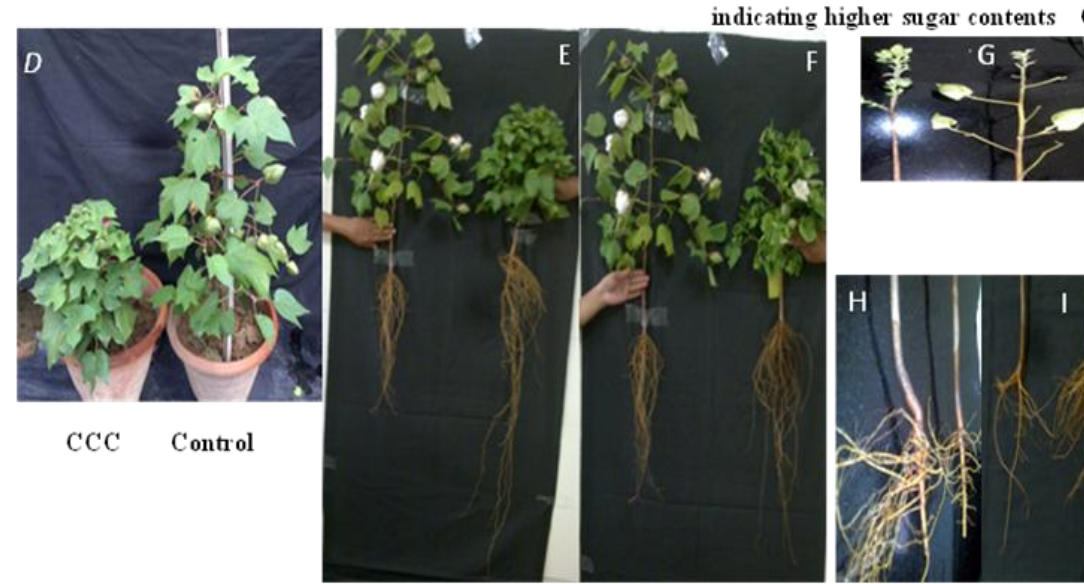

$\mathrm{CCC}$

Control

Control $\quad \mathrm{CCC}+\mathrm{Urea}$

Control $\mathrm{CCC}+$ Potash $\mathrm{CCC}$ Control $\mathrm{CCC}$ Internodes reduction by cycocel

Figl. Growth (leaf shape and size, plant height, compactness, branching pattern, main root thickness and root length of cotton plant with cycocel treatment in combination with nitrogen (urea) and potassium (murate of potash)

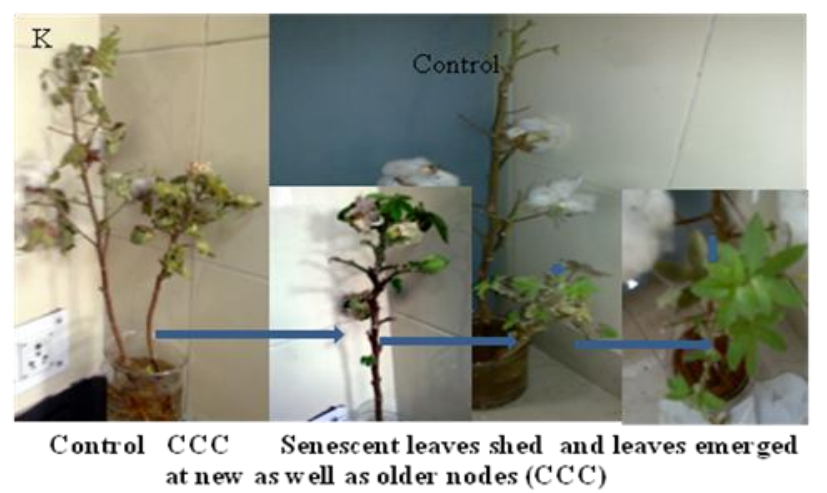
at new as well as older nodes (CCC)

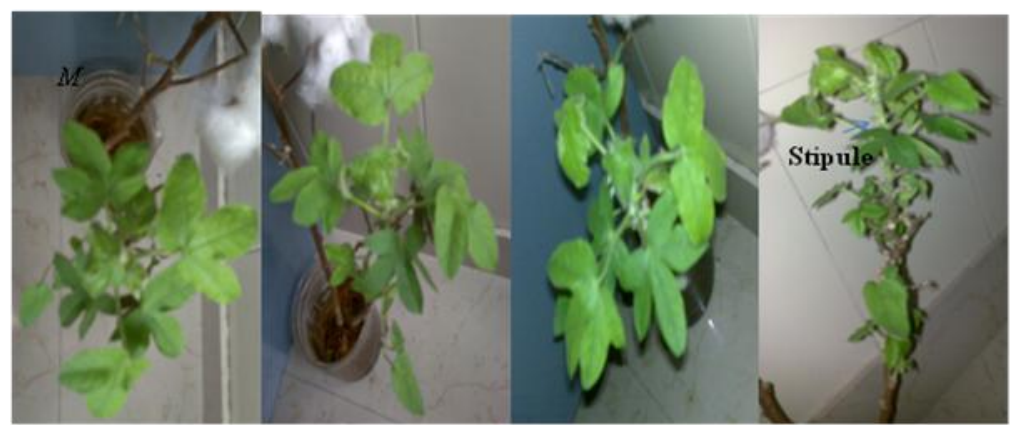

L eaves with differ ent number of lobes and larger leaves with nyctinastic movements after $\operatorname{lng} \mathrm{K}$ application in $500 \mathrm{ml}$ of tap water

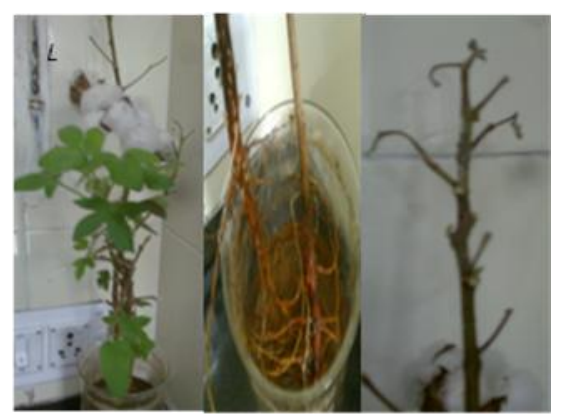

$\mathrm{CCC} \quad$ New emerging roots Control 


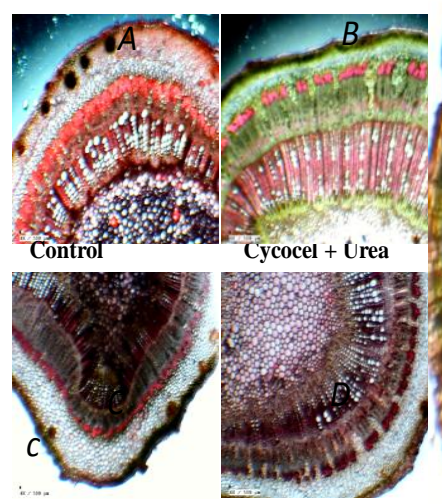

Cycocel

Cycocel +Potassium

Fig 2. Stem anatomy displaying xylem fibers and xylem vessels sizes and distribution under various treatments in cotton

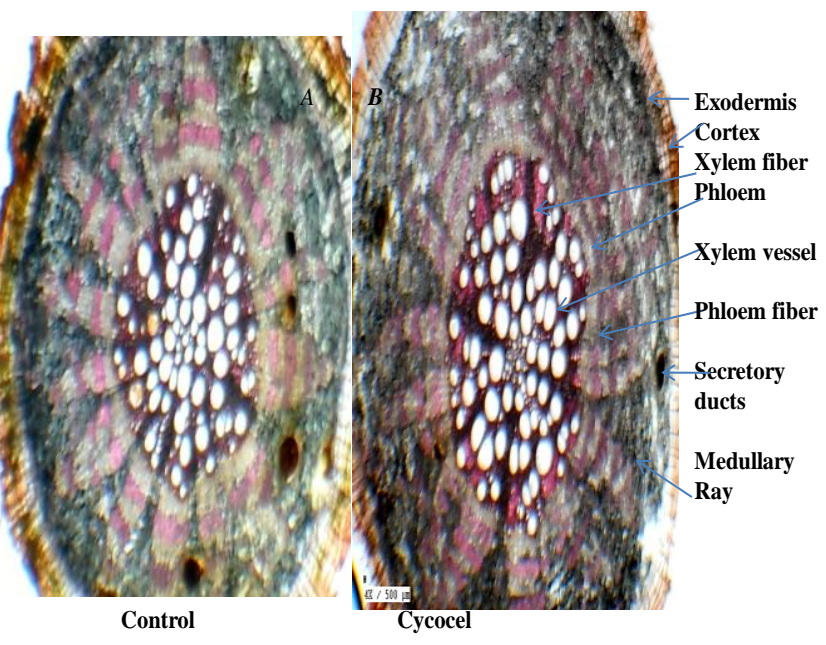

Root anatomy displaying increased diameter by phloem fiber or bast formation in $\mathrm{CCC}$ treated plants $(B)$

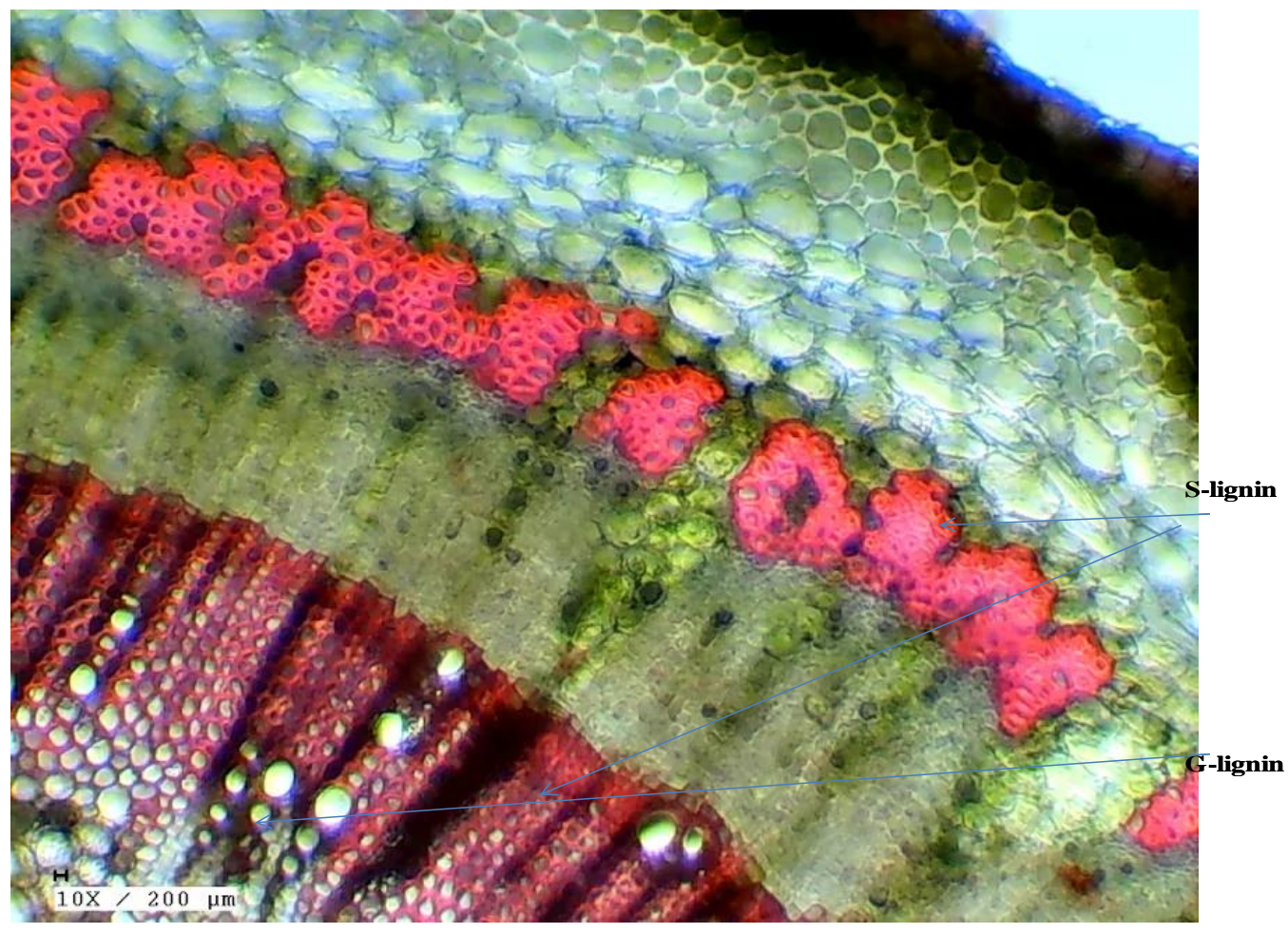

Fig 3. Lignin distribution in transverse section of cotton stem from control 

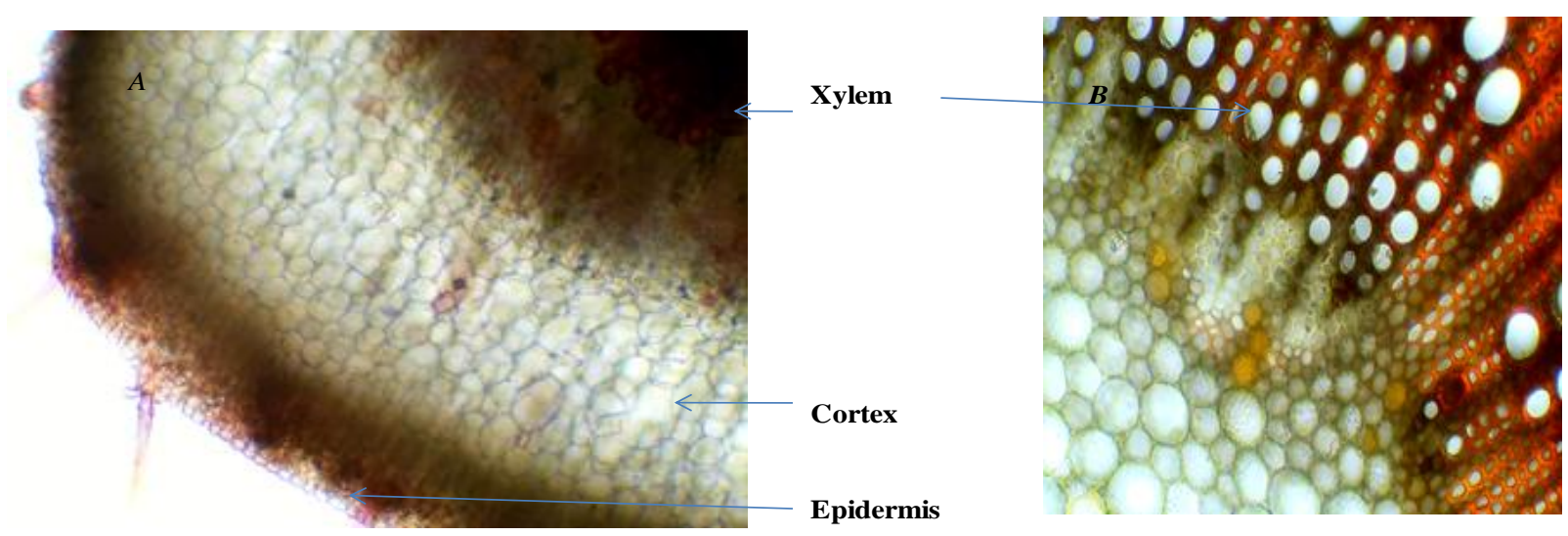

Fig 4. Potassium increased cell size/volume/turgor of node bearing leaves showing rhythmic movement with light in retardant treated plants applied during regenerating apex in cycocel treated plant (A) control plant $(B)$ died

Lamina thickness and dark green color has been associated with decorative value and longevity of leaves in ornamental crops that bring higher profitability to the growers. Cytokinin and abscisic acid have been associated with developmental control of cambium in sunflower under nitrogen application and under combination of high temperature, radiation and water stress in late sown wheat (Santosh Kumari, 2017 Santosh Kumari, 2013,Santosh Kumari, 2010). Our study reveals that cotton crop growth can be managed by careful application of split doses of $\mathrm{N}$ and $\mathrm{K}$ at different stages of internode elongations under the influence of cycocel to balance the vegetative (leaf formation) and reproductive stages (ball formation and defoliation plus opening of bolls) as suggested by Santosh Kumari (2009).

\section{Acknowledgement}

Help provided in Light microscopy by Pharmacology Department of AIIMS, Delhi is thankfully acknowledged.

\section{References}

Macmillan CP, Birke H, Bedon F, Pettolino FA (2013) Lignin Deposition in Cotton Cells - Where is the lignin? J
Plant Biochem Physiol 1:e106. doi:10.4172/2329-9029.1000e106

Lu P., Outlaw Jr. W.H., Smith B.G., Freed G.A. 1997 A new mechanism for the regulation of stomatal aperture size in intact leaves: Accumulation of mesophyll-derived sucrose in the guard-cell wall of Vicia faba. Plant Physiol 114: 109-118

Mengel K., Kirkby E.A. 2001. Principles of Plant Nutrition. $\left(5^{\text {th }}\right.$ ed.) vol. 35. Kluwer Academic Publishers, Dordrecht, The Netherlands, pp. 11591160.

Marschner P. 2012 Marschner's Mineral Nutrition of Higher Plants. Elsevier Ltd. Amsterdam, p. 651.

Santosh Kumari (2009). Kapas ki kheti mein potassium ka mahatav. Pusa Surbhi (Hindi), IARI.

Santosh Kumari (2010). Cellular changes and their relationship to morphology, abscisic acid accumulation and yield in wheat (Triticum aestivum) cultivars under water stress. American J. Plant Physiol.5(5), 257-277. ISSN 15574539doi: 10.3923/ajpp.2010.257.277

Santosh Kumari (2017).Effects of nitrogen levels on anatomy, growth, and chlorophyll content in sunflower (helianthus annuus 1.) leaves. J. Agric. 
Sci. 9(8): 208-219.

Talbott, L.D. and Zeiger, E. (1996) Central roles for potassium and sucrose in guard-cell osmoregulation. Plant Physiol. 111, 1051-1057.

$\mathrm{Xu} \mathrm{L,} \mathrm{Zhu} \mathrm{L,} \mathrm{Tu} \mathrm{L,} \mathrm{Liu} \mathrm{L,} \mathrm{Yuan} \mathrm{D,} \mathrm{et} \mathrm{al.}$ (2011)Lignin metabolism has a central role in the resistance of cotton to the wilt fungus Verticillium dahliae as revealed by RNA-Seq-dependent transcriptional analysis and histochemistry. J Exp Bot 62: 56075621. doi:10.1093/jxb/err245

Zahoor R., Zhao W., Dong H., et al.(2017). Potassium improves photosynthetic tolerance to and recovery from episodic drought stress in functional leaves of cotton (Gossypium hirsutum L.). Pl. Physiol. Biochem. 119:21-32.

\section{How to cite this article:}

Santosh Kumari and Vipin Kumar Verma 2019. Cycocel Induced Lignin Deposition in Cotton Cells and its Role in Crop Growth. Int.J.Curr.Microbiol.App.Sci. 8(03): 1567-1573. doi: https://doi.org/10.20546/ijcmas.2019.803.181 